\title{
Population Growth Overshooting and Trade in Developing Countries
}

\author{
Ulla Lehmijoki \\ University of Helsinki \\ HECER
}

\author{
Tapio Palokangas \\ University of Helsinki \\ HECER and IZA
}

\author{
University of Helsinki \\ Department of Economics \\ Discussion Paper No. 621:2005 \\ ISBN 952-10-2764-9, ISSN 1459-3696
}

December 7, 2005

\begin{abstract}
This paper examines a developing economy by a family-optimization model in which the number of children is a normal good in preferences. Trade liberalization generates two effects: an income effect, which raises population growth in the short run; and a gender wage effect, which decreases that in the long run. With higher income, families invest more in capital. Because female labor is more complementary to capital, a higher level of investment increases women's relative wages and attracts more of them from child rearing into production. Consequently, the population growth rate falls below the original level in the long run. This paper also provides some empirical evidence on these results.
\end{abstract}

Journal of Economic Literature: O41, J13, J16

Keywords: population growth, international trade

Addresses of Authors: Ulla Lehmijoki, Department of Economics, P.O. Box 17 (Arkadiankatu 7), FIN-00014 University of Helsinki, Finland (email: Ulla.Lehmijoki@helsinki.fi) - Tapio Palokangas, Department of Economics, P.O. Box 17 (Arkadiankatu 7), FIN-00014 University of Helsinki, Finland. Phone (email: Tapio.Palokangas@helsinki.fi) 


\section{Introduction}

After World War II, there has been an intense endeavor for economic integration. The Bretton Woods conference and the foundation of GATT led to increase in world trade with average $7.3 \%$ per year from 1960 to 1968 and with $9.3 \%$ per year from 1968 to 1973. After the oil crisis world trade continued to expand but only at a lower rate (Page 1994). Has this trade liberalization had any impact on population growth? Has there been different demographic patterns in the short and long runs? To answer these questions, we develop an open-economy population growth model and support its results by empirical evidence. We suggest that world trade liberalization has led to an exogenous income shock that in turn has induced considerable demographic effects in developing countries. ${ }^{1}$

In developing countries, women's labor market participation has been restricted by rigid gender roles and religious rules (Neumayer and de Soysa 2005). Since these are slow to change, trade liberalization rewarded families mainly through men's higher wages, while women stayed home in childrearing. This has considerably promoted population growth in the short run.

In the long-run, however, the gender wage gap has tapered off. An emerging empirical literature considers the role of international trade in closing the gender wage gap. Ghiara (1999) shows that the liberalization period 1987-93 in Mexico has narrowed this gap in service sector but widened it in manufacturing. Berik (2000) finds that the 1980 trade reform in Taiwan have adversely affected wages but yet reduced the gender wage gap. The same was repeated in Brazil after the 1990 liberalization (Santos and Arbache 2005). Using data on 161 occupations in 80 countries for the period 1983-99, Oostendorp (2004) shows that trade narrowed the gender gap only in lowskill but not in high skill occupations. In this paper, we concentrate on the demographic effects and show that narrowing gender wage gap has increased the opportunity cost for child-rearing encouraging women to produce rather than reproduce. In the future, the population growth rate may "overshoot" in developing countries - it may fall even below the level that prevailed before

\footnotetext{
${ }^{1}$ Recent theories argue that population growth results endogenously from increases in income, technical progress, and the accumulation of human and physical capital (Becker 1981, Galor and Weil 2000, Lucas 2002, Becker et al. 1990, Tamura 2002).
} 
trade liberalization.

Figure 1 shows that demographic profiles in developing countries exhibit overshooting as explained above. Take for example South Korea, the textbook case of an outward-oriented policy. Its systematic trade promotion led to record-breaking results: during the first two five year plans (1962-71) its exports grew at annual rate $40 \%$ (Ray 1998). The GDP share of Korea's trade (exports and imports) was only $5.99 \%$ in 1953 but increased to $86.31 \%$ in 2000. The simultaneous demographic overshooting was record-breaking as well. Figure 1 shows that population growth of $1.38 \%$ in 1955 rocketed to $3.35 \%$ in 1960 . Later, the continuous increase in trade was accompanied by population growth slow down to $1.39 \%$ in 1979 (Maddison 2003).

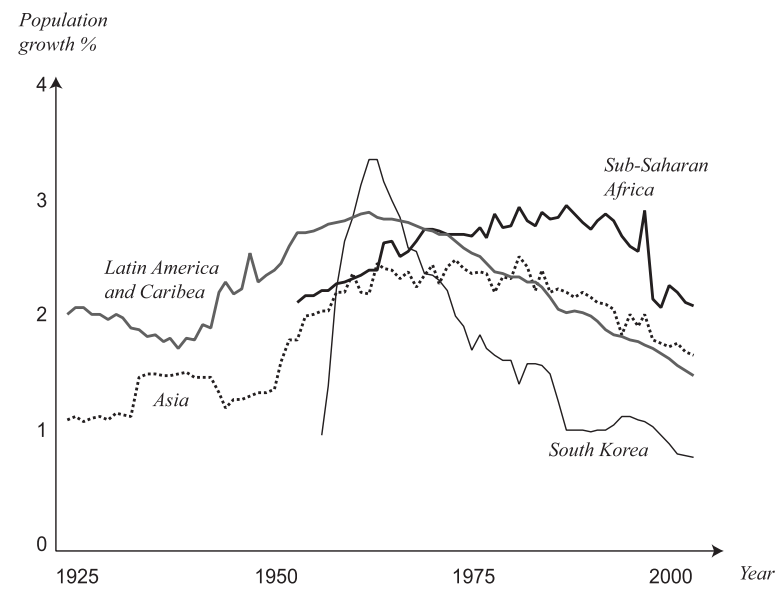

Figure 1: Population growth in Latin America and Caribea (17 countries), Asia (12 countries), Sub-Saharan Africa (20 countries) and South Korea. Data source: Maddison 2003.

An opposite experience is Sub-Sahara. One of the greatest reason for its poor economic performance is likely its inward-directed policy and failure to remove trade restrictions (for a review, see Collier and Cunning 1999). As a result, Sub-Saharan economies have experienced several long lasting recessions. Figure 1 shows that Africa has experienced not only an economic but also a demographic tragedy. So far, here has been only the short run effect that promotes population growth, but the long run effect that decreases population growth has not yet been fully realized. 
The remainder of this paper is organized as follows. We consider the short-run and long-run demographic effects of trade liberalization. Sections 2 and 3 presents a continuous-time family-optimization model with endogenous fertility. Sections 4 and 5 construct the long-run and short run dynamics of the economy after liberalization. Following Galor and Weil (1996), we assume that mental abilities are complementary to capital and women with their smaller body size have comparative advantage in these abilities. For these reasons in the long run, capital deepening closes the gender wage gap and increases the opportunity cost of child bearing. Section 6 supports these results by empirical evidence.

\section{Families}

Consider an infinitely living representative family of $L$ members with an equal number $L / 2$ of both men and women. The family derives utility from per capita consumption $c$ and the number of children that can be proxied by the population growth rate $n$ (Razin and Ben-Zion, 1975, and Becker 1981). We specify the family's discounted utility at time $t=0$ as follows:

$$
U=\int_{0}^{\infty}(\log c+\psi n) e^{-\rho t} d t
$$

in which $\rho>0$ is the constant rate of time preference and the constant $\psi>0$ gives the weight for children in household's preferences. In the function (1), the income elasticity is higher for the number of children, $n$, than for per capita consumption $c$. This characterizes the case of a developing country in which households are close to the subsistence minimum and population growth is very sensitive to income through the decrease in child mortality.

In line with Galor and Weil (1996), we assume the following production and child-rearing technology. All men and women can divide their working time between child-rearing and the labor market. On the assumption that each newborn requires one unit of men's or women's working time, the family's time devoted to child rearing is equal to the number of newborns $\dot{L} \doteq d L / d t=n L$, where $t$ is time and $n \doteq \dot{L} / L$ the population growth rate. The economy contains only one asset, (physical) capital, and three factors of production, capital, physical labor and mental labor. Men are superior in 
bodily strength but have equal abilities with women in mental labor. This property is specified so that in the labor market one unit of men's working time is transformed into one unit of both mental and physical labor, while one unit of women's labor time into one unit of mental labor.

Given the difference in factor endowment between men and women, the opportunity cost of raising children is higher for a man than for a woman. For a sufficiently low relative wages for mental labor, women raise children full time. As the relative wage of mental labor increases, women may join the labor force and increase gradually the fraction of their time devoted to market labor. Thus, all $L / 2$ men are in the labor market. If the women devote $n L$ units of their labor time to child-rearing, their supply the rest $L / 2-n L=$ $(1 / 2-n) L$ in the labor market. This means that the men supply $L / 2$ units of physical and $L / 2$ units of mental labor, the women supply $(1 / 2-n) L$ units of mental labor, the total supply of physical labor is equal to $L / 2$, and the total supply of mental labor is equal to $L / 2+(1 / 2-n) L=(1-n) L$.

Capital complements mental labor more than physical labor: an increase in capital raises the marginal product of mental labor proportionally more than it raises the marginal product of physical labor. Galor and Weil (1996) compose a production function which incorporates this property in a simple way: capital and mental labor are complements in production, whereas physical labor is neither a complement nor a substitute the other inputs. We modify this production function as follows. There are two sectors. In the physical-labor sector, one unit of output is produced from one unit of physical labor. In the mental-labor sector, output $Y$ is produced from capital $K$ and mental labor $(1-n) L$ through the strictly concave, linearly homogenous, and twice differentiable function

$$
Y=F((1-n) L, K), \quad F_{1}>0, \quad F_{2}>0, \quad F_{11}<0, \quad F_{22}<0, \quad F_{12}>0,
$$

in which the subscript $i \in\{1,2\}$ of $F$ denotes the partial derivative of $F$ with respect to the $i$ th argument from the left.

The relative prices of all goods are given from the world market. We choose the units so that the prices of consumption goods, investment goods and the output of the mental-labor sector are equal to unity. Our key hypothesis is that in developing countries trade liberalization increases the output price $p$ in the physical-labor sector. This can be justified as follows. Before 
liberalization, the industrialized countries are relatively well and the developing countries relatively poorly endowed with capital. Consequently, trade liberalization decreases the relative price for capital-intensive goods in the developing countries. Because the mental-labor sector uses capital, then its relative price $1 / p$ must fall and $p$ must rise.

Families consume and invest in capital and the household budget constraint can be written in terms of capital accumulation as follows:

$$
\dot{K} \doteq d K / d t=p L / 2+Y-c L
$$

in which $p L / 2$ is income from the physical-labor sector, $Y$ that from the mental-labor sector, $c$ per capita consumption and $c L$ total consumption. Noting (2) and defining the capital-labor ratio $k \doteq K / L$, the family's budget constraint (3) can be expressed in per capita terms as follows:

$$
\dot{k}=\frac{\dot{K}}{L}-\frac{K}{L} \frac{\dot{L}}{L}=\frac{p}{2}+F(1-n, k)-c-n k .
$$

\section{Optimal resource allocation}

The family chooses per capita consumption $c$ and the population growth rate $n$ to maximize its utility (1), given its budget constraint (4). The Hamiltonian of this optimization is given by

$$
H=\log c+\psi n+\lambda[p / 2+F(1-n, k)-c-n k],
$$

in which the co-state variable $\lambda$ evolves according to

$$
\dot{\lambda}=\rho \lambda-\partial H / \partial k=\left[\rho+n-F_{2}(1-n, k)\right] \lambda, \quad \lim _{t \rightarrow \infty} \lambda k e^{-\rho t}=0 .
$$

The first-order conditions for the control variables $c$ and $n$ are given by

$$
\partial H / \partial c=1 / c-\lambda=0, \quad \partial H / \partial n=\psi-\left[F_{1}(1-n, k)+k\right] \lambda=0 .
$$

Given these two equations and (2), we define per capita consumption as a function of capital $k$ and the population growth rate $n$ :

$$
\begin{aligned}
& c(k, n) \doteq 1 / \lambda=\left[F_{1}(1-n, k)+k\right] / \psi, \\
& \partial c / \partial k=\left(F_{12}+1\right) / \psi>0, \quad \partial c / \partial n=-F_{11} / \psi>0 .
\end{aligned}
$$


Capital accumulation (i.e., a higher $k$ ) increases output and per capita consumption c. As normal goods, per capita consumption (i.e. $c$ ) and the number of children (i.e., $n$ ) are positively associated.

To obtain a rough approximate of the trade-income ratio, we assume that the developing economy imports only investment goods. It then follows from the constraint (3) that to import the amount $\dot{K}$ the economy exports the output of the physical-labor sector, $p L / 2$, plus the output of the mental-labor sector net of domestic consumption, $Y-c L$. Noting (2), (7) and $k=K / L$, the trade-income ratio is then

$$
\begin{aligned}
& x(p, k, n) \doteq \frac{p L / 2+Y-c L}{p L / 2+Y}=1-\frac{c(k, n)}{p / 2+F(1-n, k)} \in(0,1), \quad \frac{\partial x}{\partial p}>0 \\
& \frac{\partial x}{\partial k}=(1-x)\left[\frac{F_{2}}{p / 2+F}-\frac{1}{c} \frac{\partial c}{\partial k}\right], \frac{\partial x}{\partial n}=(x-1)\left[\frac{F_{2}}{p / 2+F}+\frac{1}{c} \frac{\partial c}{\partial n}\right]<0 .
\end{aligned}
$$

The increase in the population growth rate $n$ decreases the trade-income ratio $x$ through two channels. First, it transfers women from production into child-rearing and decreases output. Thus, the proportion of output not consumed at home (= exported) rises. Second, because consumption and and the number of children are positively associated as normal goods, consumption and the proportion of output consumed at home increases and the proportion of output exported decreases. Investment in capital $k$ has two opposite effects on the ratio $x$. It increases income and consumption. On the other hand, it increases women's productivity in manufacturing and thereby attracts women from child rearing into production. Because the difference of production and consumption is exported, the net effect is ambiguous.

\section{Long-run dynamics}

From the family's budget constraint (4) it follows that trade liberalization (i.e., an increase in $p$ ) produces an immediate income effect in the economy. Given the production function (2), we obtain the values of the marginal products of physical and mental labor are $p$ and $F_{1}$, respectively. Because one unit of men's working time is transformed into one unit of both mental and physical labor, but one unit of women's working time into one unit of mental labor, men earn the wage $p+F_{1}$ but women earn the wage $F_{1}$ per 
unit of time. The women's relative wage is then given by

$$
\omega(p, n, k) \doteq \frac{F_{1}(1-n, k)}{p+F_{1}(1-n, k)}, \quad \frac{\partial \omega}{\partial k} \doteq \frac{-p F_{12}}{\left(p+F_{1}\right)^{2}}=-p \frac{F_{12}}{F_{1}} \frac{\partial \omega}{\partial p}>0 .
$$

This shows that after the occurrence of trade liberalization (i.e., a higher $p$ ) there exists a gender wage effect through capital accumulation as follows. With bigger capital $k$ but for a given population growth rate $n$, a woman's marginal product $F_{1}$ and wage $\omega$ increase. This attracts women from childrearing to production and increases total output.

Inserting (7) into the differential equation (4), capital accumulation $\dot{k}$ can be defined as a function of the variables $(n, k, p)$, for which

$$
\begin{aligned}
& \partial \dot{k} / \partial n=-F_{1}-k-\partial c / \partial n=-\psi c-\partial c / \partial n<-\psi c<0, \\
& \partial \dot{k} / \partial k=F_{2}-n-\partial c / \partial k, \quad \partial \dot{k} / \partial p=1 / 2>0 .
\end{aligned}
$$

Given the function (7), we can transform the differential equation (6) into

$$
\rho+n-F_{2}(1-n, k)=\frac{\dot{\lambda}}{\lambda}=-\frac{\dot{c}}{c}=-\left(\frac{1}{c} \frac{\partial c}{\partial k}\right) \dot{k}-\left(\frac{1}{c} \frac{\partial c}{\partial n}\right) \dot{n} .
$$

Inserting (9) into this equation and noting (2), the change of the population growth rate, $\dot{n}$, can be defined as a function of the variables $(n, k, p)$, for which

$$
\begin{aligned}
& \left.\frac{\partial \dot{n}}{\partial n}\right|_{\dot{k}=\dot{n}=0}=-\left(\frac{1}{c} \frac{\partial c}{\partial n}\right)^{-1}\left[F_{12}+1+\left(\frac{1}{c} \frac{\partial c}{\partial k}\right) \frac{\partial \dot{k}}{\partial n}\right] \\
& =-(\underbrace{\frac{1}{c} \frac{\partial c}{\partial n}}_{+})^{-1}(\underbrace{F_{12}+1}_{+})[1+\underbrace{\frac{1}{\psi c} \frac{\partial \dot{k}}{\partial n}}_{<-1}]>0, \\
& \left.\frac{\partial \dot{n}}{\partial k}\right|_{\dot{k}=\dot{n}=0}=\left(\frac{1}{c} \frac{\partial c}{\partial n}\right)^{-1}\left[F_{22}-\left(\frac{1}{c} \frac{\partial c}{\partial k}\right) \frac{\partial \dot{k}}{\partial k}\right], \\
& \left.\frac{\partial \dot{n}}{\partial p}\right|_{\dot{k}=\dot{n}=0}=-\left(\frac{1}{c} \frac{\partial c}{\partial n}\right)^{-1}\left(\frac{1}{c} \frac{\partial c}{\partial k}\right) \frac{\partial \dot{k}}{\partial p}=-\frac{1}{2}(\underbrace{\frac{1}{c} \frac{\partial c}{\partial n}}_{+})^{-1}(\underbrace{\frac{1}{c} \frac{\partial c}{\partial k}}_{+})<0 .
\end{aligned}
$$

From the steady-state conditions $\dot{k}=\dot{n}=0$ and the equation (10) it follows that $F_{2}(1-n, k)=\rho+n$. In this system of two equations $\dot{k}=0$ and 
$F_{2}(1-n, k)=\rho+n$, variables $(k, n)$ are endogenous and $p$ is exogenous. Differentiating this system totally and noting (2), (7) and (9), we obtain

$$
A>0 \Leftrightarrow \frac{\partial n}{\partial p}=\frac{1}{A} \frac{F_{22}}{A} \frac{\partial \dot{k}}{\partial p}<0 \Leftrightarrow \frac{\partial k}{\partial p}=\frac{1}{A}(\underbrace{F_{12}+1}_{+}) \frac{\partial \dot{k}}{\partial p}>0,
$$

where the Jacobian $A$ is given by

$$
\begin{aligned}
A & =-\left(F_{12}+1\right) \frac{\partial \dot{k}}{\partial k}-F_{22} \frac{\partial \dot{k}}{\partial n}<-\left(F_{12}+1\right) \frac{\partial \dot{k}}{\partial k}+F_{22} \psi c \\
& =-\psi \frac{\partial c}{\partial k} \frac{\partial \dot{k}}{\partial k}+F_{22} \psi c=\psi c\left[F_{22}-\frac{1}{c} \frac{\partial c}{\partial k} \frac{\partial \dot{k}}{\partial k}\right] .
\end{aligned}
$$

From (2), (12) and (13) it follows that after the increase in the relative price $p$ there are two alternative patterns of long-run development:

(i) With $A>0$, the population growth rate $n$ falls, but the capital-labor ratio $k$ and per capital income $p / 2+F(1-n, k)$ rise.

(ii) With $A<0$, the population growth rate $n$ rises, but the capital-labor ratio $k$ and per capital income $p / 2+F(1-n, k)$ fall.

Because the case (i) is consistent but the case (ii) is in contradiction with empirical evidence (see section 6 ), we choose $A>0$. We conclude:

Proposition 1 In the long run, trade liberalization (i.e., a higher $p$ ) increases capital $k$ and decreases the population growth rate $n$.

This result is interpreted in at the end of the next section.

\section{Short-run dynamics}

From (2), (7), (11), (12) and (13) it follows that

$$
0>F_{22}>\frac{1}{c} \frac{\partial c}{\partial k} \frac{\partial \dot{k}}{\partial k}, \quad \frac{\partial \dot{k}}{\partial k}<0,\left.\quad \frac{\partial \dot{n}}{\partial k}\right|_{\dot{k}=\dot{n}=0}>0 .
$$

In the system, capital $k$ is a state variable, while the population growth rate $n$ is (as a substitute for the shadow price $\lambda$ ) the co-state variable. Given 


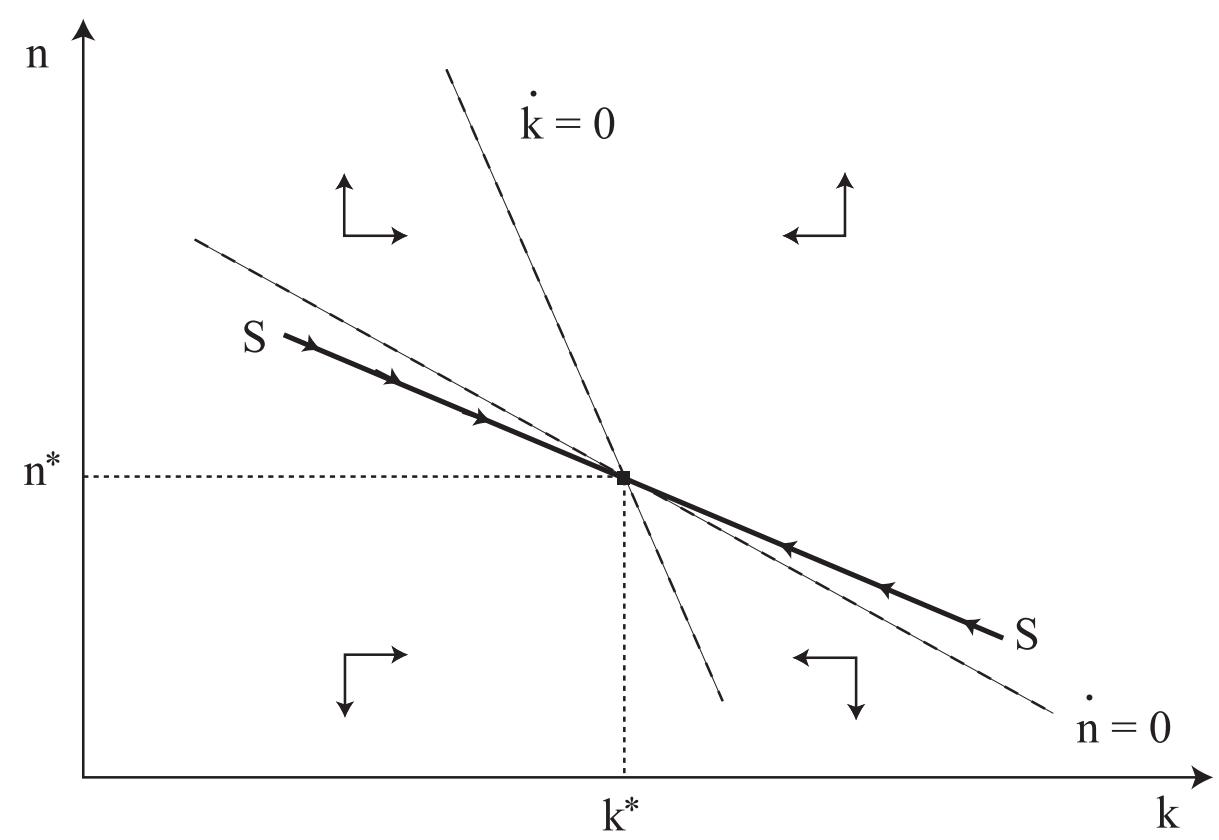

Figure 2: The saddle point

(9), (11) and (14), the comparative static properties of the system in the $(k, n)$-plane are the following [Fig. 2]. From the saddle point condition

$$
\underbrace{\frac{\partial \dot{k}}{\partial k}}_{-} \underbrace{\frac{\partial \dot{n}}{\partial n}}_{+}<\underbrace{\frac{\partial \dot{k}}{\partial n}}_{-} \underbrace{\frac{\partial \dot{n}}{\partial k}}_{+} \text {or } \underbrace{\frac{\partial \dot{k}}{\partial k}}_{-} / \underbrace{\frac{\partial \dot{k}}{\partial n}}_{-}>\underbrace{\frac{\partial \dot{n}}{\partial k}}_{+} / \underbrace{\frac{\partial \dot{n}}{\partial n}}_{+},
$$

it follows that both singular curves $(\dot{k}=0)$ and $(\dot{n}=0)$ are decreasing, but the curve $(\dot{k}=0)$ falls steeper than the curve $(\dot{n}=0)$,

$$
\left.\frac{\partial n}{\partial k}\right|_{\dot{k}=0}=-\frac{\partial \dot{k}}{\partial k} / \frac{\partial \dot{k}}{\partial n}<-\frac{\partial \dot{n}}{\partial k} / \frac{\partial \dot{n}}{\partial n}=\left.\frac{\partial n}{\partial k}\right|_{\dot{n}=0}<0 .
$$

Assume now that the system is initially in the steady state $\left(k_{0}, n_{0}\right)$, but the price $p$ increases. From (9), (11) and (14) it follows that

$$
\left.\frac{\partial k}{\partial p}\right|_{\dot{k}=0}=-\underbrace{\frac{\partial \dot{k}}{\partial p}}_{+} / \underbrace{\frac{\partial \dot{k}}{\partial k}}_{-}>0,\left.\quad \frac{\partial k}{\partial p}\right|_{\dot{n}=0}=-\underbrace{\frac{\partial \dot{n}}{\partial p}}_{-} / \underbrace{\frac{\partial \dot{n}}{\partial k}}_{+}>0 .
$$

Tus, the curves $(\dot{k}=0)$ and $(\dot{n}=0)$ shifts to the right [Fig. 3]. In the long run, $k$ rises but $n$ falls, $k_{0}<k_{1}$ and $n_{0}>n_{1}$. From (11) it follows that when 


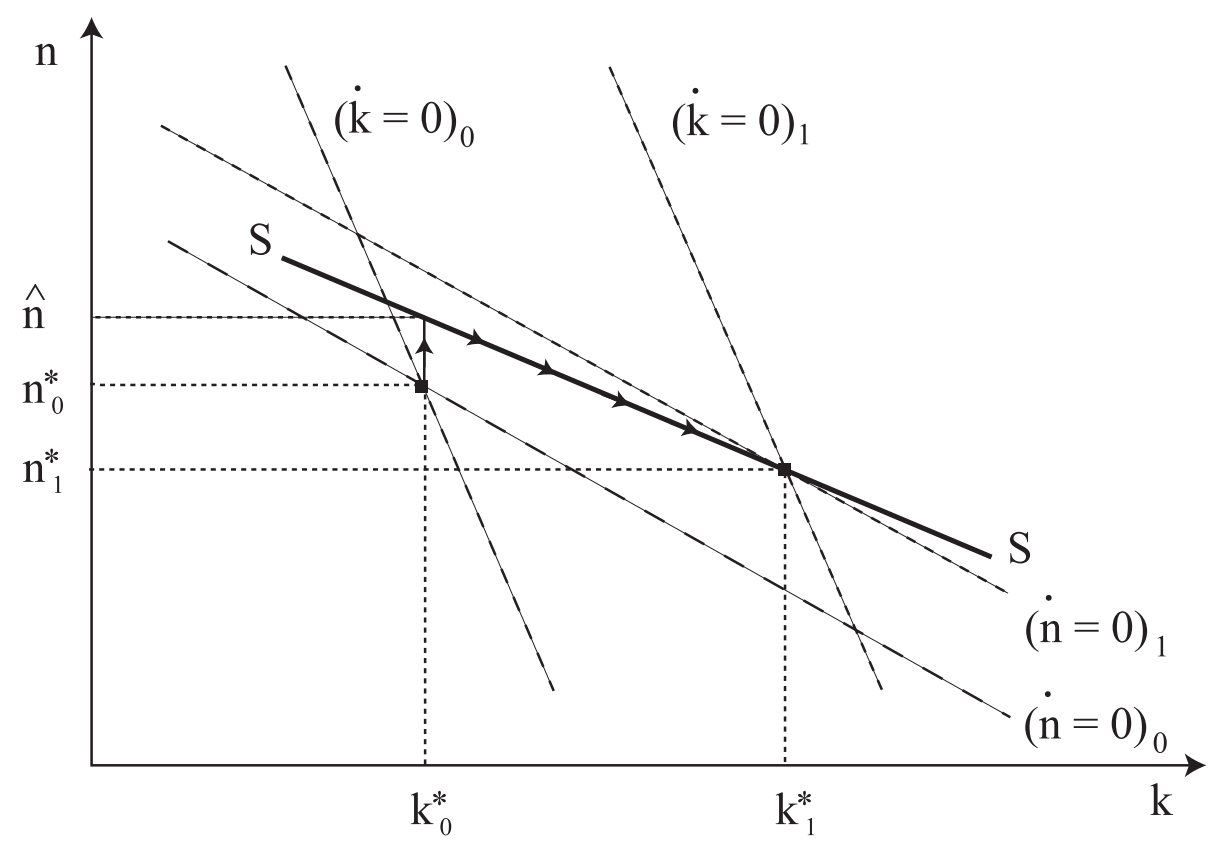

Figure 3: The dynamics of the model

$p$ increases, the co-state variable $n$ jumps upwards from $n_{0}$ to $\hat{n}$,

$$
\left.\frac{\partial n}{\partial p}\right|_{\dot{n}=0}=-\underbrace{\frac{\partial \dot{n}}{\partial p}}_{-} / \underbrace{\frac{\partial \dot{n}}{\partial n}}_{+}>0 .
$$

After this, the system evolves along the saddle path $S S$ to the new steady state $\left(k_{1}, n_{1}\right)$ [Fig. 3]. Thus, a higher $p$ raises $n$ and $c$ through (7).

Proposition 2 In the short run, trade liberalization (i.e., a higher $p$ ) increases the population growth rate $n$ and per capita consumption $c$.

Finally, consider the trade-income ratio $x$ or (8). At the moment $t=0$, trade liberalization (i.e., a higher $p$ ) has the following effect on $x$ :

$$
\underbrace{\frac{\partial x}{\partial p}}_{+}+\underbrace{\frac{\partial x}{\partial n}}_{-} \underbrace{\left.\frac{\partial n}{\partial p}\right|_{\dot{n}=0}}_{+}
$$

Thus, if the direct effect $\partial x / \partial p>0$ dominates over the indirect effect through the population growth rate $n$, then the trade-income ratio $x$ increases at the 
moment $t=0$. Next, consider any short time interval $d t$ after the moment $t=0$. In that interval, the development of $x$ is determined by

$$
\underbrace{(\partial x / \partial k)}_{?} \dot{k}+\underbrace{(\partial x / \partial n)}_{-} \dot{n} .
$$

Thus, if the effect through population growth, $(\partial x / \partial n) \dot{n}$, dominates over the effect through capital accumulation, $(\partial x / \partial k) \dot{k}$, then the trade-income ratio increases during the time interval $d t$. Thus, $x$ increases both at the moment $t=0$ and during any interval after it. We conclude:

Proposition 3 If the direct effect of trade liberalization dominates over its effect through population growth and its effect through population growth outweighs that through capital accumulation, then the occurrence of trade liberalization generates a positive trend for the trade-income ratio.

In developing countries, trade liberalization first increases and then decreases the population growth rate. This can be explained as follows. Before liberalization, industrialized countries are abundant and developing countries are poor in capital. Thus, international trade increases the relative price $p$ for the physical-labor sector which less capital intensive in developing countries. With a higher price $p$, the families earn more and save more in capital. Because the number of children is a normal good in the family preferences, higher income raises the population growth rate in the short run. On the other hand, because capital and mental labor are complements, and because women have comparative advantage in mental labor, capital deepening raises women's wages and attracts them from child rearing into production. In the long run, the number of women in child rearing decreases so much that the population growth rate falls below the original level.

\section{Some empirical evidence}

The theoretical model above predicts that trade liberalization — via increasing income and closing gender wage cap - induces an overshooting in population growth in developing countries. Given the post-war liberalization, Figure 1 (page 2) shows that the revealed demographic profiles follow the pattern suggested by the model. 
Unfortunately, the available data for trade and control variables only go back to 1960 and some of them are available in quinquennial series alone. Therefore, it is not possible to perform a complete dynamic analysis of time paths to verify the causality from trade liberalization to population growth. Instead, we argue that because trade has a positive trend, it can be used as a proxy for time. ${ }^{2}$ Therefore, a regression of population growth against trade should exhibit the predicted dynamic process i.e., overshooting in the meaning that trade first boosts and then curbs population growth. ${ }^{3}$

We collected data for period 1960-99 from 53 low and middle income countries with populations larger than one million. ${ }^{4}$ Population growth, however, is an aggregate number, much determined by inherited age structure. Because we want to concentrate on reproductive behavior, we take the total fertility rate $T F R$ (the number of children per woman) as the regressand to the model. Further, since we want to know the number of survivals rather than the number of births per se, the infant mortality rate MORTIN is controlled for. Data for these variables are provided by United Nations (2003) in quinquennial series. ${ }^{5}$ There are eight observations for each country. Full descriptive statistics and the list of countries are given in the Appendix.

We take the GDP-share of the sum of exports and imports as the measure of trade and denote it by TRADE. The data come from the Penn World Table (Heston et al. 2002). ${ }^{6}$ We estimate a quadratic function between $T F R$ and TRADE with critical value TRADE $<78.62$ below (above) which the association is positive (negative). For significance test, we apply interactive dummy technique with the interactive dummy INTRACT $=D \cdot T R A D E$ in which $D=0(1)$ for $T R A D E<78.62(T R A D E>78.62)$ is the intercept

\footnotetext{
${ }^{2}$ In spite of some protectionist episodes, the positive time trend was significant at $0.08 \%$ level in the sample of 53 developing countries used below.

${ }^{3}$ The model predicts that population growth ultimately falls below the original level but this has not yet realized in developing countries.

${ }^{4}$ China and Rwanda not included.

${ }^{5}$ During the research period, the sample average of total fertility was 5.40 children per woman; the highest value 8.20 was reached in Niger (both in 1975-97 and 1980-84) while the lowest value 1.51 was reached in South Korea (in 1995-99). The average infant mortality during the research period was 90.78 (per thousand births). The highest (217.60) and lowest (7.79) values were reached in Mali 1960-64 and in Korea 1995-99 respectively.

${ }^{6}$ For a review of measuring trade, see Edwards 1997. Trade ranges from 60.24 in 1960-64 to 71.47 in $1995-99$.
} 
dummy. Altogether, we estimate ${ }^{7}$

$$
T F R=\alpha+\beta_{1} D+\beta_{2} \text { TRADE }+\beta_{3} \text { INTERACT }+\beta_{4} \text { PERIOD }+\varepsilon,
$$

in which PERIOD refers to the eight quinquennial periods. The $O L S$ estimates for a pooled panel are given by regression 1 in Table 1 . The results support overshooting; for TRADE $<78.62$ the estimated coefficient is 0.0175 whereas for $T R A D E>78.62$ the estimated coefficient is $0.0175-0.0181=$ -0.0006 . The overshooting is statistically significant. ${ }^{8}$

To illustrate the result, consider a (hypothetical) economy with minimum observed trade $T R A D E=3.84$ initially (see Appendix). After liberalization the initial income effect increases fertility by $(78.62-3.84) * 0.0175=1.31$ children per woman. Later on, fertility starts to decrease due to the gender wage effect. If trade increases to the maximal observed value TRADE = 233.58 , fertility would decrease by $(233.58-78.62) * 0.0006=0.01$ children per woman i.e., only slightly. Therefore, the gender wage effect merely eliminates the initial fertility-boosting income effect of trade liberalization.

Recent studies suggest several alternative determinants for fertility (see Kelley and Schmidt 2005 and Galor 2005 for review). Therefore, we include GDP, FEMLAB, and NOSCHOOL to control for per capita GDP (assumed to capture technical progress), female labor force participation rate, and the share of adult women without schooling respectively. ${ }^{9}$ The data come from Heston et al. (2002), Barro-Lee data-set (1993), and World Bank (2004). ${ }^{10}$ Bongaarts and Cotts Watkins (1996) together with Caldwell (1982 and 2001) claim that diffusion of family planning practices and westernization of values has played an important role in fertility decline. One can argue that liberal, non-autocratic governments have performed policies that have favored diffusion during the adjustment to trade liberalization. To control this, we

\footnotetext{
${ }^{7}$ To linearize the model GDP and MORTIN come in logs. Observations with mean \pm $2 \cdot s t d$ are excluded as outliers.

${ }^{8}$ The $p$-values are 0.0000 and 0.0093 for TRADE and INTERACT.

${ }^{9} F E M L A B$ comes in the estimated modification $(F E M L A B-33.70)^{2}$. Since GDP and FEMLAB may be endogenous to fertility, we apply the beginning-of-period values for each quinquennial period.

${ }^{10}$ The Barro-Lee data-set is continued to 1999 by assuming that the change in NOSCHOOL from 1995 to 1999 was identical to the change from 1990 to 1995 in each country. Occasionally missing individual observations are replaced by the closest available value.
} 


\begin{tabular}{|c|c|c|c|}
\hline Model & 1 & 2 & 3 \\
\hline \multirow{2}{*}{ TRADE } & 1.75 & 1.28 & 1.32 \\
\hline & $(6.56)$ & $(5.41)$ & $(5.51)$ \\
\hline \multirow[t]{2}{*}{ INTRACT } & -1.81 & -1.46 & -2.11 \\
\hline & $(-2.62)$ & $(-2.55)$ & $(-3.68)$ \\
\hline \multirow[t]{2}{*}{$\operatorname{logMORTIN}$} & 203.98 & 130.48 & 127.08 \\
\hline & $(23.47)$ & $(10.05)$ & $(9.70)$ \\
\hline \multirow[t]{2}{*}{ PERIOD } & -11.26 & -12.41 & -13.53 \\
\hline & $(-6.41)$ & $(-6.25)$ & $(-6.54)$ \\
\hline \multirow[t]{2}{*}{$\log \mathrm{GDP}$} & & -36.45 & -36.88 \\
\hline & & $(-4.67)$ & $(-3.64)$ \\
\hline \multirow[t]{2}{*}{ sqFEMLAB } & & 0.24 & 0.12 \\
\hline & & $(5.07)$ & (2.50) \\
\hline \multirow[t]{2}{*}{ NOSCHOOL } & & 0.36 & 0.79 \\
\hline & & $(1.55)$ & $(2.83)$ \\
\hline \multirow[t]{2}{*}{ AUTOCRACY } & & 5.62 & 3.94 \\
\hline & & $(4.62)$ & (3.19) \\
\hline \multirow[t]{2}{*}{ SSA } & & & 46.65 \\
\hline & & & $(2.34)$ \\
\hline \multirow[t]{2}{*}{ LAC } & & & 55.99 \\
\hline & & & (3.48) \\
\hline \multirow[t]{2}{*}{ ASIA } & & & -10.19 \\
\hline & & & $(0.58)$ \\
\hline \multirow[t]{2}{*}{ INTSSA } & & & 0.12 \\
\hline & & & $(0.49)$ \\
\hline \multirow[t]{2}{*}{ INTLAC } & & & 0.31 \\
\hline & & & $(1.32)$ \\
\hline \multirow[t]{2}{*}{ INTASIA } & & & 1.23 \\
\hline & & & $(4.16)$ \\
\hline $\mathrm{R}^{2}$ & 0.69 & 0.75 & 0.78 \\
\hline Observations & 361 & 361 & 361 \\
\hline
\end{tabular}

Table 1: OLS regressions for total fertility rate TFR. Heteroscedasticity corrected standard errors used. All coefficients multiplied by 100 . $t$-values in parenthesis. 
include the variable $A U T O C R A C Y$ which measures the autocracy of the governance (for details, see Marschall and Jaggers 2002). The data come from the University of Maryland's Polity IV Project (Marschall and Gurr 2005).

The estimated coefficients for this model are given in regression 2 in Table 1. Again, they support overshooting. For TRADE $<78.62$ (TRADE $>$ $78.62)$ the estimated coefficient is $0.0128(-0.0016)$. As usually, the coefficients for the per capita income and the female participation rate are significant. Further, regression 2 shows the important role of autocracy and also that the variable NOSCHOOL is insignificant. A possible interpretation is that if modern family planning methods are available and socially acceptable (caught by variable $A U T O C R A C Y$ ), and if women have an incentive to limit their reproduction (caught by variable $F E M L A B$ ), then education is not an important determinant of fertility. In particular, this implies that low education is not an obstacle to the efficient use of family planning.

Figure 1 shows that demographic differences are remarkable among developing countries in different areas. To capture these differences we introduce areal intercept and interactive dummy groups to the extent that these groups are significant. The intercept dummies are $S S A$ (Sub-Sahara), LAC (Latin America and Caribea), and ASIA (Asia). It turns out that only the interactive dummies for $T R A D E>78.62$ are significant. These are denoted by INTSSA, INTLAC, and INTASIA respectively.

Regression 3 reports the estimates that show overshooting in Sub-Sahara and Latin America and Caribea (negative interactive dummy INTRACT big and significant, areal interactions insignificant) but no overshooting in Asia, where the estimated coefficient for $T R A D E>78.62$ is positive. This is somewhat counterintuitive since Asian economies are well-known exporters of modern manufactures, such as mechanic and electronic components, the production of which well fits to women. The puzzle may be explained by the religious fundamentalism emerged especially in the Middle East. ${ }^{11}$ Another explanation is suggested by Lehmijoki and Palokangas (2005) who claim that

\footnotetext{
${ }^{11}$ For example in Jordan, trade increased from $34.11 \%$ in $1960-65$ to $132.80 \%$ in 1995 99. In spite of this, female participation rate increased only from $12.80 \%$ to $17.09 \%$ and fertility remained at a high level (4.87 children per women in 1995-99).
} 
militarism maintains high fertility in developing countries. ${ }^{12}$

Despite of the Asian puzzle, all regressions show that trade liberalization generates two effects: (a) an income effect that boosts population growth, and (b) a gender wage effect that later on alleviates population growth.

\section{Conclusions}

In this paper, we examine population growth overshooting in response to trade liberalization by a family-optimization model with endogenous population growth. In addition to capital, output is produced from physical and mental labor, with women having comparative advantage in the latter. Following Galor and Weil (1996), we assume that mental labor and capital are complements. The key assumption of the study is that in developing countries trade liberalization increases the output price in the sector using relatively more physical labor. The main result is that trade liberalization first increases population growth through the income effect, but later the gender wage effect decreases fertility during endogenous transition to new equilibrium. We find some empirical support to overshooting.

While a great deal of caution should be exercised when a highly stylized population growth model is used to draw conclusions about the structural change in developing countries, the following judgement nevertheless seems to be justified. In many developing countries, the trade policy history with a short post-war liberal period and a considerable protectionist period soon after may have had unfortunate demographic consequences. It is possible that the trade restrictions in the 70 s and 80 s suggested by the PrebishSinger argument slowed down capital accumulation and thereby prolonged the period of high population growth, because the initial income shock due to initial trade liberalization has already taken place. Due to this policy, the population of the developing economies may now be considerably larger than in the absence of the Prebish-Singer trade restrictions.

\footnotetext{
${ }^{12}$ In militarized Syria, for instance, high fertility and high levels of trade have occurred simultaneously.
} 


\section{Appendix}

\begin{tabular}{lrrrr}
\hline \hline Variable & Mean & Std.Dev. & Min & Max \\
\hline Total fertility rate & 5.40 & 1.58 & 1.51 & 8.20 \\
Trade & 62.47 & 39.81 & 3.84 & 233.58 \\
Infant mortality rate & 90.78 & 47.97 & 7.79 & 217.60 \\
GDP per capita, constant prices & 3076.03 & 2355.40 & 295.08 & 14182.20 \\
Female labor force, share of total & 34.91 & 9.89 & 10.10 & 54.13 \\
No schooling, share of adult females & 58.89 & 29.29 & 0.30 & 99.90 \\
Autocracy of governance & 3.60 & 3.30 & 0.00 & 10.00 \\
& & & & \\
\hline \hline
\end{tabular}

Table 2: Descriptive statistics.

Countries: Argentina, Bangladesh, Benin, Bolivia, Botswana, Brazil, Cameroon, Central African Republic, Colombia, Congo (Dem. Rep), Congo (Rep.), Costa Rica, Dominican Republic, Egypt, El Salvador, Gambia, Guatemala, Honduras, India, Jamaica, Jordan, Kenya, South Korea, Lesotho, Malawi, Malaysia, Mali, Mauritius, Mexico, Mozambique, Nepal, Nicaragua, Niger, Pakistan, Panama, Papua New Guinea, Paraguay, Peru, Philippines, Senegal, Sierra Leone, South Africa, Sri Lanka, Syria, Thailand, Togo, Trinidad and Tobago, Tunisia, Turkey, Uganda, Uruguay, Zambia, Zimbabwe.

\section{References:}

Aghion, P. and Durlauf, S. (2005): Handbook of Economic Growth, Volume 1B. Elsevier.

Barro, R. and Lee, J.W. (1993): "International Measures of Schooling Years and Schooling Quality." American Economic Review, Papers and Proceedings 86, 218-223.

Becker, G.S. (1981): A Treatise on the Family. Gambridge, Massachusetts: Harvard University Press.

Becker, G.S., Murphy, K.M., and Tamura, R. (1990): "Human Capital, Fertility, and Economic Growth." Journal of Political Economy 98, S12-S37.

Berik, G. (2000): "Mature Export-Led Growth and Gender Wage Inequality in Taiwan." Feminist Economics 6, 1-26. 
Bongaarts, J. and Cotts Watkins, S. (1996): "Social Interactions and Contemporary Fertility Transitions." Population and Development Review 22, 639-682.

Caldwell, J.C. (1982): Theory of Fertility Decline. London: Academic Press. Caldwell, J.C. (2001): "The Globalization of Fertility Behavior." Population and Development Review 27, 93-115.

Collier, P. and Gunning, J.W. (1999): "Explaining African Economic Performance." Journal of Economic Literature XXXVII, 64-111.

Edwards, S. (1997): "Trade Policy, Growth, and Income Distribution." American Economic Review 87, 205-210.

Galor, O. and Weil, D.N. (1996): "Gender Gap, Fertility, and Growth." American Economic Review 86, 374-387.

Galor, O. and Weil, D.N. (2000): "Population, Technology, and Growth: From Malthusian Stagnation to the Demographic Transition and beyond." American Economic Review 90, 806-826.

Galor, O. (2005): "From Stagnation to Growth: Unified Growth Theory." Chapter 4 in Aghion and Durlauf.

Ghiara, R. (1999): "Impact of Trade Liberalization on Female Wages in Mexico: An Econometric Analysis." Development Policy Review 17, 171-190.

Heston, A., Summers, R., and Aten, B. (20002): "Penn World Table Version 6.1, Center for International Comparisons at the University of Pensylvania (CICUP). U.S.A.

Kelley, A.C. and Schmidt, R.M. (2005): "Evolution of Recent EconomicDemographic Modelling: A Synthesis." Journal of Population Economics 18, 275-300.

Lehmijoki, U. and Palokangas, T. (2005): "Political Instability, Gender Discrimination, and Population Growth in Developing Countries." Journal of Population Economics, Forthcoming.

Lucas, R.E. Jr (2002): Lectures on Economic Growth. Cambridge, Massachusetts: Harvard University Press.

Maddison, A. (2003): The World Economy, Historical Statistic, CD-ROM. Paris: OECD.

Marshall, M.G. and Gurr, T.R. (2005): Peace and Conflict. Center for International Development \& Conflict Management. University of Maryland. http://www.cidcm.umd.edu.

Marshall, M. G. and Jaggers, K. (2002): Polity IV Project. Dataset User's Manual. University of Maryland. U.S.A.

Neumayer, E. and de Soysa, I. (2005): Globalization, Women's Economic Rights and Forced Labor. Manuscript. 
Oostendorp, R.H. (2004): "Globalization and the Gender Wage Gap." Policy Research Working Paper 3256. Washington DC: World Bank.

Page, S. (1994): How Developing Countries Trade. London: Routledge.

Razin, A. and Ben-Zion, U. (1975): "An Intergenerational Model of Population Growth." American Economic Review 65, 923-933.

Ray, D. (1998): Development Economics. Princeton: Princeton University Press.

Santos, M.H.C.P. and Arbache, J.S. (2005): Trade Openness and Gender Discrimination. Manusctipt.

Tamura, R. (2002): "Human Capital and Switch from Agriculture to Industry." Journal of Economic Dynamics and Control 27, 207-242.

United Nations (2003): World Population prospects: The 2002 version. CDrom. New York.

World Bank (2004): World Development Indicators 2004. On-line Version. 